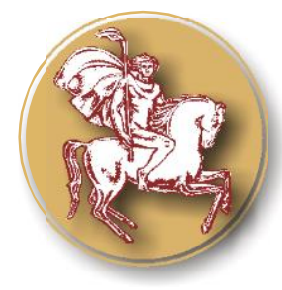

Trakia Journal of Sciences, No 4, pp 309-313, 2021

Copyright (C) 2021 Trakia University

Available online at:

http://www.uni-sz.bg

ISSN 1313-3551 (online)

doi:10.15547/tjs.2021.04.004

Original Contribution

\title{
PROFESSIONAL STRESS AND BURN-OUT SYNDROME AMONG EMPLOYEES IN UNIVERSITY HOSPITAL KASPELA
}

\author{
M. Doykov ${ }^{1}$, V. Stoyanov ${ }^{2}$, K. Trifonova ${ }^{2}$, K.Slaveykov ${ }^{2 *}$ \\ ${ }^{1}$ Department of Urology, Medical University Plovdiv, Bulgaria \\ ${ }^{2}$ Department of Ophthalmology and Otorhinolaryngology Trakia University, Stara Zagora, Bulgaria
}

\begin{abstract}
Purpose: The contemporary work place creates a challenge towards physicians and their teams. They are forced into a situation, in which to be competitive they must have skills outside of their medical specialty, such as health management, pedagogy, information and communication technologies.

Methods: An adapted 55 question questionnaire was used and analyzed with One-way ANOVA, Correlation and multiple regression analysis in SPSS.

Results and conclusion: Despite the physicians and their teams reporting high levels of workload and stress, the satisfaction from work hasn't diminished and the evaluation for the quality of provided work is still high. Additional research into the topic is required with focus on comparison between hospital physicians and primary care physicians.
\end{abstract}

Key words: stress, burnout syndrome, medical professionals

\section{INTRODUCTION}

Contemporary medicine is characterized by intensive development in science and technologies, as well as increased competition between different participants in the health service market. The elevated requirements for knowledge, skills expertise and organizational behavior towards medical specialists lead to consistent professional stress.

Work place stress has consequences on personal, interpersonal and organizational level and requires high adaptation capacity in medical workers to overcome. The current pandemic has only increased the strain and pressure on the healthcare work force and burnout had become a common problem that must be addressed.

*Correspondence to: Kiril Slaveykov, Trakia University, Stara Zagora, Department of Ophthalmology and Otorhinolaryngology, kirilslaveykov@gmail.com,tel.0886712078
Even without the pandemic, the medical profession is stressful. The long hours, night shifts, constant need to update your knowledge, uncertainties during procedures, and medical errors build up. This pressure is initially "invisible", but if measures are not taken could lead to severe symptoms and even diseases (1). Burnout or burnout syndrome (BOS) is defined as a psychological syndrome that may emerge when employees are exposed to a stressful working environment with high job demands and low resources (2). In the medical field, burnout is even more problematic, as it endangers both the health and well-being of the healthcare worker and the patients, due to a decrease in quality of care and a higher chance of medical error (3). The existing literature on the subject lists' death, and suffering of patients, insufficient training, conflict with colleagues, lack of social support, excessive workload and uncertainty about a treatment given as the major stress factors for nurses (4). The major stress factors for physicians are physicians; the factors are time pressure, 
conflict between career, and family, delayed gratification, loss of autonomy and in some cases research and teaching activities (5). Physician assistants, medical technicians and administrative staff demonstrate the highest association with stress the following factors - job strain, overcommitment and social support (6). Recognizing indicators and risk factors for burnout and addressing these issues on system-wide and profession-wide levels may help to mitigate professional pressures and improve healthcare provider satisfaction and fulfillment (7).

\section{AIM}

To analyze the level of stress and burn-out among the medical employees in the hospital care

\section{MATERIALS AND METHODS}

Healthcare professionals from one University private hospital in Bulgaria participated. All questionnaires were filled after informed consent, during the time period January - March 2021. Out of the 133 returned 130 were finished correctly and usable, with a return rate of $97,7 \%$.

As a basis, we used the Maslach self-assessment questionnaire, which we simplified and adapted for our needs. We still retained the three main categories: emotional exhaustion, depersonalization and personal accomplishments (8).
DOYKOV M., et al. The questionnaire included gender, age, work experience, marital status, current position, working hours, night shifts work and several perceived scales on how work has affected them. Each item was graded on a 5-point scale (1strongly disagree, 2 - disagree, 3 - uncertain, 4 agree, 5 - strongly agree).

One-way analysis of variance was used for the analysis of burnout according to the sociodemographic information, profession, work conditions and level of job strain. Correlation analysis was performed to analyze the relationships among independent variables influencing burnout. Multiple regression analysis for different models was performed to identify the factors influencing work-related burnout. All calculations were performed using the software SPSS V.16, with the level of significance set at $\mathrm{p}<0.05$.

\section{RESULTS AND DISCUSSION}

The participants were mainly female $-63,8 \%$, with nurses slightly outnumbering physicians $561,2 \%$ for the former, to $43,8 \%$ for the latter. Mean age was 40,7 years, with mean working experience 16 years. More than half were married - 60,8\%. Participants were predominantly in surgical specialties $-56,2 \%$ (Table 1). There are high levels of emotional exhaustion $(33,1 \%)$, depersonalization $(51,5 \%)$ and low levels of job satisfaction (60\%) (Figure 1).

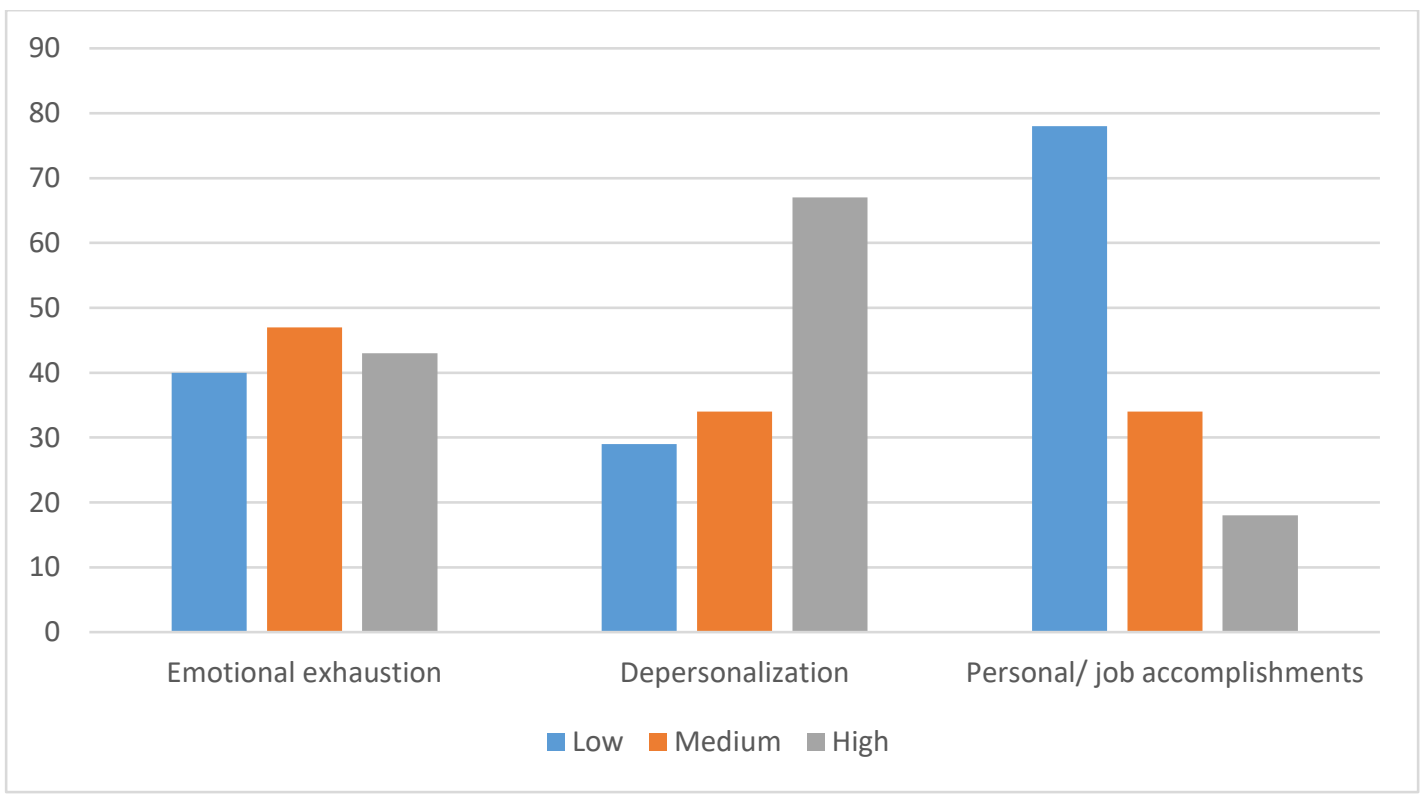

Figure 1. Level of emotional exhaustion, depersonalization and personal/ job accomplishments 
Table 1. Characteristics of participants

\begin{tabular}{|c|c|c|c|}
\hline \multicolumn{2}{|c|}{ Factor } & $\mathbf{N}$ & Percent \\
\hline \multirow[t]{2}{*}{ Gender } & Male & 47 & 36,2 \\
\hline & Female & 83 & 63,8 \\
\hline \multirow[t]{5}{*}{ Age } & $<30$ & 30 & 23,1 \\
\hline & $30-40$ & 35 & 26,9 \\
\hline & $40-50$ & 32 & 24,6 \\
\hline & $50-60$ & 27 & 20,8 \\
\hline & $>60$ & 6 & 4,6 \\
\hline \multirow[t]{2}{*}{ Marital status } & Married & 79 & 60,8 \\
\hline & Single & 47 & 39,2 \\
\hline \multirow[t]{2}{*}{ Profession } & Physician & 57 & 43,8 \\
\hline & Nurse & 73 & 56,2 \\
\hline \multirow[t]{7}{*}{ Work experience } & $<5$ & 33 & 25,4 \\
\hline & $5-10$ & 24 & 18,5 \\
\hline & $10-15$ & 12 & 9,2 \\
\hline & $15-20$ & 21 & 16,2 \\
\hline & $20-25$ & 5 & 3,8 \\
\hline & $25-30$ & 12 & 9,2 \\
\hline & $>35$ & 23 & 17,7 \\
\hline \multirow{2}{*}{$\begin{array}{c}\text { Specialty type / } \\
\text { department }\end{array}$} & Surgical & 73 & 56,2 \\
\hline & Internal & 57 & 43,8 \\
\hline \multirow[t]{2}{*}{ Day / Night shifts } & Yes & 109 & 83,8 \\
\hline & No & 21 & 16,2 \\
\hline \multirow[t]{2}{*}{ 24-hours on call } & Yes & 109 & 83,8 \\
\hline & No & 21 & 16,2 \\
\hline
\end{tabular}

During the One-way ANOVA and Correlation analysis the following factors showed statistically significant influence on stress and burn-out:

Gender: Males report less barriers when communication with patients $(p=0,041$, Pearson Correlation $=-0,180)$, feel full of energy $(p=0,017$, Pearson Correlation $=-0,209)$, feel refreshed after working with patients $(p=0,025$, Pearson Correlation $=-0,197)$, have less complaints of arterial hypertension $(p=0,006$, Pearson Correlation=0,239) and headache $(p=0,019$, Pearson Correlation $=0,205)$ and fell less stressed due to insufficient payment $(p=0,026$, Pearson Correlation $=0,196)$. They are more stressed due to insufficient time with patients $(p=0,004$, Pearson Correlation $=$ $0,250)$, unwanted phone calls $(p=0,034$, Pearson Correlation $=-0,187)$ and scientific work $(p=0,019$, Pearson Correlation $=-0,206)$.

Age - With aging people felt that they work too much $(p=0,040$, Pearson Correlation $=0,180)$, their work emotionally depletes $(p<0,021$,
Pearson Correlation=0,202) and destroys them $(p=0,005$, Pearson Correlation=0,207). Older medical provider report they are at their end of their power $(p=0,002, \quad$ Pearson Correlation $=0,272$ ), do their work with displeasure $\quad(p=0,002, \quad$ Pearson Correlation $=0,273$ ) and feel the patients blame them for their problems $(p=0,011$, Pearson Correlation $=0,223$ ). With age they suffer more from arterial hypertension ( $p<0,001$, Pearson Correlation $=-0,419)$, lack of interest $(p=0,023$, Pearson Correlation $=0,200$ ) and reduced working speed $\quad(p=0,034, \quad$ Pearson Correlation=0,186).

Marital status: Married health providers solve problems easier $(p=0,002$, Pearson Correlation $=$ $-0,275)$, feel that their work is positively influencing them $(p=0,048, \quad$ Pearson Correlation $=-0,176)$ and have achieved positive results $(p=0,025$, Pearson Correlation $=-0,199)$. Single responders report weight loss $(p=0,048$, Pearson Correlation=0,176). 
Profession - Physicians report less barrier with patient communication $(p=0,042$, Pearson Correlation $=-0,179)$ and more energy $(p=0,042$, Pearson Correlation $=-0,179$ ). Nurses are more stressed from insufficient payment $(p=0,015$, Pearson Correlation=0,212) and report higher levels of arterial hypertension ( $p=0,014$, Pearson Correlation $=0,215$ ), while physicians are more stressed from insufficient time with patients $(p=0,024$, Pearson Correlation $=-0,198)$ and having to balance clinical and scientific work $(p=0,032$, Pearson Correlation $=-0,188)$.

Work experience - With the increase of work experience medical practitioners start to feel emotionally depleted $(p=0,009, \quad$ Pearson Correlation $=0,230$ ), the stress from working with people becomes unbearable $(p=0,010$, Pearson Correlation=0,227), they start to feel that their work is destroying them $(p=0,003$, Pearson Correlation=0,225), feel at the end of their power $\quad(p=0,001, \quad$ Pearson Correlation $=0,290)$, do their work with displeasure $\quad(p=0,006, \quad$ Pearson Correlation $=0,238$ ) and feel that patients are blaming them for their problems $(p=0,026$, Pearson Correlation=0,193). Strangely there is inversely proportional relationship between arterial hypertension and work experience $(p<0,001$, Pearson Correlation = -0,339),

Specialty - Medical practitioners in surgical departments report easier time understanding patients $(p=0,019$, Pearson Correlation $=-0,205)$ and solving their problems $(p=0,005$, Pearson Correlation $=-0,246)$, feeling of positive achievements in their work $(p=0,004$, Pearson Correlation $=-0,248)$, but also increased stress in the work place $(p=0,014$, Pearson Correlation= -0,216).

Day / Night shifts - Responders giving day and/ or night shifts report positive feeling of achievements $\quad(p=0,018, \quad$ Pearson Correlation $=0,207)$, more stress from negative influence on family life $(p=0,040$, Pearson Correlation $=0,181$ ), changes in behavior $(p=0,007, \quad$ Pearson $\quad$ Correlation $=0,234)$, increased alcohol usage $(p=0,018$, Pearson Correlation $=0,207)$ and loss of humor $(p=0,036$, Pearson Correlation=0,184).
DOYKOV M., et al. 24-hour availability - those who are on call 24hours feel tired when coming to work $(p=0,022$, Pearson Correlation=0,201), are stress from unethical behavior of colleagues $(p=0,027$, Pearson Correlation=0,197), suffer from loss of initiative $(p=0,036$, Pearson Correlation $=0,184)$ and increased workplace stress $(p=0,001$, Pearson Correlation=0,186). They also report reduced working speed $(p=0,019$, Pearson Correlation $=0,206)$, problems sleeping $(p=0,039$, Pearson Correlation $=0,181)$, behavior changes $(p=0,016$, Pearson Correlation $=0,211)$, feeling irritable $(p=0,044, \quad$ Pearson Correlation $=0,177)$ and loss of humor $(p=0,008$, Pearson Correlation=0,233).

The factor found having statistically significant effect was then run through a Multiple regression analysis. Gender remained a significant factor for arterial hypertension $(\mathrm{p}=0,037)$, insufficient payment $(\mathrm{p}=0,032)$ and scientific work $(p=0,019)$. Age influenced arterial hypertension $(p=0,042)$ and feelings of working too much $(\mathrm{p}=0,025)$. Marital status only influences problem solving $(\mathrm{p}=0,046)$. Profession remains significant for energy level $(\mathrm{p}=0,039)$, payment stress $(\mathrm{p}=0,014)$ and scientific work-related stress $(\mathrm{p}=0,013)$. Work experience remain only significant for incidents of arterial hypertension $(\mathrm{p}=0,005)$. Specialty is related to increased stress in the work place $(\mathrm{p}=0,035)$. Giving day or night shifts is only statistically significant for feeling of achievement ( $\mathrm{p}=0,019)$, while being 24 -hour on call loses its significance.

A similar study by Dimitrova et al focused on medical students finds $21.8 \%$ have high level of emotional depletion, $50,3 \%$ depersonalization and $88,8 \%$ low levels of job satisfaction, concluding that while the results are concerning it is not too late to take measures in the first three years of education (9).

Poncet et al burnout syndrome in ICU, with results showing a severe BOS in nearly a third of the nurses $(32,8 \%)$. Similarly to our study gender, work experience and marital status were significant factor for BOS (10).

Another study on burnout in nurses found that there were statistically significant differences in burnout levels associated with age, gender, marital status, having children, level of 
healthcare, type of work shift, healthcare service areas and conducting administrative tasks. While we haven't examined level of healthcare and children the other factor are also significant in our study (11).

Embriaco et al examine the levels of burnout among ICU healthcare professionals. The team finds organization, duration of working hours, conflicts within the ICU, communication among healthcare workers, and the management of endof-life cares the leading determinants for BOS, which again are factor we also find significant (12).

Even when dealing with professions as strenuous as medicine, some specialties are more burdensome than others. Whippen et al examine the levels of BOS in oncologists as one of the most stressful specialties. The study fins insufficient personal and/or vacation time, continuous exposure to fatal illness, frustration with limited therapeutic success and the uncertainty as to the future of reimbursement for physician services the major factor contributing the high levels of BOS (13). Of the listed lack of personal time and reimbursement were also significant factors in our study.

\section{CONCLUSION}

These are just preliminary results from a pilot study. We are still collecting questionnaires from hospitals from all over the country and while the number of participants is relatively small it shows interesting correlations. Burnout is a serious problem, especially in the medical field, which should not be underestimated. The medical profession is highly stressful, with high levels of emotional exhaustion, depersonalization and low levels of job satisfaction. The pandemic further exacerbates the situation and pushes healthcare workers to the brink of their abilities. Further research on the topic is needed with a comparison of BOS before and after the pandemic.

\section{REFERENCES}

1. Maslach C, Schaufeli WB. Historical and conceptual development of burnout. Prof Burnout:1-16, 1993.

2. Maslach C, Schaufeli WB, Leiter MP. Job burnout. Annu Rev Psychol; 52:397-422, 2001.
DOYKOV M., et al.

3. Klein J, Grosse Frie K, Blum K, et al. Burnout and perceived quality of care among German clinicians in surgery. Int J Qual Health Care; 22:525-30, 2010.

4. Gray-Toft P, Anderson JG. Stress among hospital nursing staff: its causes and effects. Soc Sci Med A; 15:639-47, 1981.

5. Siu C, Yuen SK, Cheung A. Burnout among public doctors in Hong Kong: cross-sectional survey. Hong Kong Med J; 18:186-92, 2012.

6. Chou LP, Li CY, Hu SC. Job stress and burnout in hospital employees: comparisons of different medical professions in a regional hospital in Taiwan. BMJ open. Feb 1;4(2), 2014.

7. Bridgeman $\mathrm{PJ}$, Bridgeman $\mathrm{MB}$, Barone J. Burnout syndrome among healthcare professionals. The Bulletin of the American Society of Hospital Pharmacists. Feb 1;75(3):147-52, 2018.

8. Maslach, C., \& Jackson, S.E. (1981b). Maslach Burnout Inventory Manual. Palo Alto, CA: Consulting Psychologists Press.

9. Dimitrova S., Foreva G, Prodanova M, Komsiiska D., Peeva K., Announcements of union of scientists - Sliven, Medical students and burnout syndrome - emperical study, Announcments of the Union of scientists Sliven, 8(3):47-49, 2014.

10. Poncet MC, Toullic P, Papazian L, KentishBarnes N, Timsit JF, Pochard F, Chevret S, Schlemmer B, Azoulay É. Burnout syndrome in critical care nursing staff. American journal of respiratory and critical care medicine. Apr 1;175(7):698-704, 2007.

11. Cañadas-De la Fuente GA, Vargas C, San Luis C, García I, Cañadas GR, Emilia I. Risk factors and prevalence of burnout syndrome in the nursing profession. International journal of nursing studies. Jan 1;52(1):240-9, 2015.

12. Embriaco N, Papazian L, Kentish-Barnes N, Pochard F, Azoulay E. Burnout syndrome among critical care healthcare workers. Current opinion in critical care. Oct 1;13(5):482-8, 2007.

13. Whippen DA, Canellos GP. Burnout syndrome in the practice of oncology: results of a random survey of 1,000 oncologists. Journal of Clinical Oncology. Oct;9(10):1916-20, 1991. 
DOYKOV M., et al. 